\title{
Editorial: The Role of Priming in Terrestrial and Aquatic Ecosystems
}

\author{
Thomas S. Bianchi ${ }^{1 *}$ and Nicholas D. Ward ${ }^{2,3}$ \\ ${ }^{1}$ Department of Geological Sciences, University of Florida, Gainesville, FL, United States, ${ }^{2}$ Marine Sciences Laboratory, \\ Pacific Northwest National Laboratory, Sequim, WA, United States, ${ }^{3}$ School of Oceanography, University of Washington, \\ Seattle, WA, United States
}

Keywords: carbon, aquatic, terrestrial, decomposition, continuum, priming

\section{Editorial on the Research Topic}

\section{The Role of Priming in Terrestrial and Aquatic Ecosystems}

The majority of organic matter (OM) in Earth's biosphere is synthesized from atmospheric carbon dioxide $\left(\mathrm{CO}_{2}\right)$ by primary producers (e.g., largely algae). The fate of this $\mathrm{OM}-$ i.e., how long it persists in the environment before being recycled back to atmospheric $\mathrm{CO}_{2}$ by heterotrophic microbes (e.g., bacteria, archaea, and fungi) and animals - is highly variable, and largely dependent on the diversity of environmental conditions it is exposed to both at its origin and during transport to distant locations. This dynamic cycling of carbon, energy, and matter between the atmosphere and biosphere occurs within and across all types of terrestrial and aquatic ecosystems. While the underlying biological functions and chemical reactions related to carbon fixation and decomposition are generally common across ecosystems, the disciplines of terrestrial and aquatic biogeochemistry have historically pursued this topic along separate paths with differing strengths and weaknesses. Although this continues today, several focus areas have recently brought more cross-fertilization between these disciplines. One such focus area where terrestrial and aquatic communities have begun converging is the study of interactive effects on OM decomposition that occur when OM of different origins and chemical composition mix. This line of research has embraced the necessity to consider reactivity within the context of the past history and present state of $\mathrm{OM}$ in all of its highly diverse forms.

Interactive effects on OM cycling were first explored about 100 years ago in the context of soil humus mineralization and have since been termed priming effects. Priming can be defined as the enhancement of recalcitrant (stable) OM breakdown via microbial decay with the addition of a more labile (less-stable) OM source. Priming can involve dissolved and/or particulate OM, in some cases accompanied by nutrients, and results in more efficient decay/consumption of stable OM material than would have occurred otherwise in the absence of the less-stable OM. While much of the work on this topic began in terrestrial systems, aquatic researchers have followed suit and gained momentum in the last decade. Observations of priming in aquatic environments are becoming more widespread, but little consensus has been reached on their importance, perhaps because we lack the mechanistic understanding to accurately predict when and where priming effects should occur. The motivation for the collection of studies summarized below is to advance a common language, set of experimental approaches, and perspective on priming effects in both terrestrial and aquatic ecosystems.

A conceptual framework for understanding how OM remineralization dynamics evolve across terrestrial landscapes and the interface between terrestrial and aquatic ecosystems was developed by Kayler et al., providing insight into how to consider the interactive influence of factors such as environmental conditions, microbe-substrate interactions such as priming effects, ecosystem connectivity, and anthropogenic perturbations on OM turnover and storage. Within 
this framework, it is suggested that the key factors governing OM remineralization and transport are (1) substrate-level properties at $\mu \mathrm{m}$ spatial and instantaneous temporal scales, (2) ecosystem properties at $\mathrm{cm}$ to $\mathrm{m}$ and daily to seasonal scales, and (3) uniand bi-directional lateral flows driven by seasonal hydrology and extreme events (Kayler et al.).

The remaining studies in this collection follow the journey of $\mathrm{OM}$ as it moves from the landscape, through rivers, and into estuarine sediments. Ward et al. examined how microbial respiration varies when rivers with different biogeochemical properties mix in the Amazon basin. It was observed that microbial consumption of dissolved $\mathrm{O}_{2}$ increased by up to 2.9 times when clearwater tributary waters were mixed with turbid Amazon River waters, presenting ecosystem scale evidence for priming effects in a setting where positive priming had previously been observed on a molecular level (Ward et al.). Textor et al. examined riverine priming effects in a contrasting settingArctic streams that receive $\mathrm{OM}$ inputs from thawing ancient permafrost. Experimental evaluation of the reactivity of dissolved OM (DOM) indicated that bulk stream DOM was not very reactive on the time scale of 28 days, but additions of permafrost, active layer soil, and vegetation leachates were quickly consumed. However, positive priming effects were not observed when simple substrates were also added (Textor et al.).

Moving from the water column to the benthos, Gontikaki and Witte examined how OM decomposition in estuarine sediments responds to two algal addition scenarios: a one-time pulse of algal detritus (e.g., after a spring algal bloom declines) and repeated deposition of small amounts of algal detritus (e.g., yearround steady inputs). In this study, neither type of algal addition resulted in a measurable priming effect, which was determined by the breakdown of a ${ }^{13} \mathrm{C}$-labeled wheat plant detritus, although the authors note high variability between cores, perhaps linked to differences in macrofaunal abundance (Gontikaki and Witte).

Aller and Cochran performed a meta-analysis of new and previously published datasets examining the role of bioturbation on OM remineralization in marine sediments. The primary proposed mechanism for stimulated OM breakdown via bioturbation is injection of reactive OM, from the water column, shallow sediments, and animal mucus, into deeper sediments. Particle mixing coefficients, indicative of these OM injection processes were well-correlated with inventories of excess radionuclides (i.e., ${ }^{234} \mathrm{Th}$ and ${ }^{210} \mathrm{~Pb}$ ) at both local and basin scales, demonstrating that plankton-derived $\mathrm{OM}$ can penetrate $\sim 5-10 \mathrm{~cm}$ into sediments over monthly timescales and 20$100 \mathrm{~cm}$ over decadal timescales (Aller and Cochran). These findings have important implications on how we evaluate the stability of OM in marine sediments.

Halvorson et al. performed a meta-analysis on the role of periphytic algae and nutrient availability in stimulating the breakdown of leaf litter in aquatic settings such as stream beds. A consistent linkage was not found between algal abundance and the stoichiometry and breakdown of leaf litter, but similar to other reviews of priming studies, large variability was observed (i.e., large positive to negative priming effects depending on location). The authors conclude that a larger sample set of priming studies examining both nutrient and carbon interactions are needed to understand how priming effects and nutrient limitation influence OM reactivity or stability (Halvorson et al.).

The general process of co-metabolism, afterwards referred to as priming, was proposed in the early to mid-twentieth century, whereby rates of soil humus mineralization were enhanced by the addition of fresh organic residues. Over the last decade, a large number of soil studies have confirmed and extended these early observations. More recently a number of studies have proposed priming in aquatic systems. However, to date there has not been a special issue on this topic that collectively examines priming in a diversity of environments. This special issue is also timely, because as we continue to change the boundaries where recalcitrant and labile materials mix in the aquatic continuum (via dams, deforestation, changes in droughts and flooding events), the role more bioavailable substrate such as algal exudates may play a more important factor in regulating carbon transformations. Understanding the importance of priming as we change Earth's landscape and aquatic critical zones will help to better understand global carbon fluxes. This special issue reports on such cases whereby the role of priming has in part, altered/controlled the dynamics of carbon processing. Moreover, these studies set the stage for linking "omics," nutrient cycling, organic geochemistry, and hydrodynamics to be understand the biogeochemical dynamics of priming in the twenty-first century.

\section{AUTHOR CONTRIBUTIONS}

TB and NW prepared the manuscript.

\section{FUNDING}

This work was supported by the University of Florida, Jon L. and Beverly A. Thompson Endowment in Geological Sciences and the US Department of Energy, Biological and Environmental Research, Subsurface Biogeochemical Research Program, grant \#DE-SC0019382.

\section{ACKNOWLEDGMENTS}

We would like to thank all of the authors who contributed to the joint Frontiers in Earth Science and Frontiers in Marine Science Research Topic: The Role of Priming in Terrestrial and Aquatic Ecosystems, the reviewers who kindly dedicated their time to the peer-review process, the Frontiers editorial team, and Dr. Elise Morrison for contributing to the Research Topic proposal.

Conflict of Interest: The authors declare that the research was conducted in the absence of any commercial or financial relationships that could be construed as a potential conflict of interest.

Copyright (c) 2019 Bianchi and Ward. This is an open-access article distributed under the terms of the Creative Commons Attribution License (CC BY). The use, distribution or reproduction in other forums is permitted, provided the original author(s) and the copyright owner(s) are credited and that the original publication in this journal is cited, in accordance with accepted academic practice. No use, distribution or reproduction is permitted which does not comply with these terms. 